\title{
PENDETEKSIAN DAN PELACAKAN LOKASI WAJAH PADA TAHAP PRA-PEMROSESAN PENGENALAN EKSPRESI MIKRO MENGGUNAKAN METODE KANADE-LUCAS-TOMASI (KLT)
}

\author{
Priska Choirina $^{1}$, Ulla Delfana Rosiani ${ }^{2}$ \\ ${ }^{1}$ Teknik Informatika, Fakultas Sains dan Teknologi, Universitas Islam Raden Rahmat Malang \\ ${ }^{2}$ Teknik Informatika, Teknologi Informasi, Politeknik Negeri Malang \\ ${ }^{1}$ priska_choirina@uniramalang.ac.id, ${ }^{2}$ rosiani@polinema.ac.id
}

\begin{abstract}
Abstrak
Penelitian dan pengamatan gerakan ekspresi mikro memerlukan tahap pre-proses yang cermat, karena berkaitan dengan pengamatan gerakan yang sangat halus dan durasi yang sangat cepat. Pada tahap ini, pendeteksian dan pelacakan area wajah harus selalu tepat agar pengamatan gerakan yang dilakukan di area wajah bisa akurat. Beberapa sampel video dataset ekspresi mikro menunjukkan adanya gerakan wajah yang diikuti dengan gerakan kecil pada bagian kepala. Gerakan-gerakan yang dihasilkan oleh kepala gerakan pada area wajah ini akan mempengaruhi kinerja dari sistem pengenalan ekspresi mikro. Penelitian ini melakukan pendeteksian dan pelacakan lokasi wajah selama terjadinya gerakan ekspresi mikro. Digunakan metode Viola-Jones untuk deteksi komponen dari wajah dan penandaan fitur titik pada setiap komponen wajah menggunakan Discriminative Response Map Fitting (DRMF). Pelacakan setiap titik fitur dilakukan dengan metode Kanade Lucas Tomasi (KLT) Setelah wajah terdeteksi dengan tepat, dilakukan pelacakan titik pada ujung hidung. Pelacakan gerakan pada ujung hidung ini diikuti oleh pembentukan area wajah. Sehingga area wajah akan selalu tepat posisinya walaupun ada gerakan di kepala. Data uji dan testing yang digunakan dalam penelitian ini adalah dataset CASME II. Pengujian dari penelitian ini diperoleh hasil bahwa pedeteksian dan pelacakan area wajah dapat dilakukan dengan tepat dan akurat pada semua data uji. Diharapkan dengan pembentukan area wajah yang selalu terlacak dengan tepat ini, proses berikutnya dari pengenalan ekspresi mikro dapat berjalan dengan baik.
\end{abstract}

Kata kunci : Deteksi wajah, Pelacakan wajah, KLT, DRMF, Viola-jones, Ekspresi mikro

\section{Pendahuluan}

Wajah merupakan bagian utama dari komunikasi yang telah menjadi target penelitian dalam computer vision sejak lama. Salah satu contoh pemanfaatan wajah dalam segi komunikasi yaitu mendeteksi ekspresi mikro pada wajah manusia. Ekspresi mikro merupakan ekspresi wajah yang terjadi ketika seseorang dalam keadaan tertekan sehingga mereka berusaha untuk menyembunyikan perasaan tersebut. Di sisi lain, ekspresi mikro terjadi dengan durasi yang cepat dan memiliki gerakan yang halus (Ekman \& Friesen, 1971) Durasi terjadinya ekspresi mikro berlangsung antara 1/5 hingga 1/25 detik (Liong et al. 2018).

Penelitian dan pengamatan gerakan ekspresi mikro memerlukan tahap pre-proses yang cermat. Hal ini karena berkaitan dengan pengamatan gerakan yang sangat halus dan durasi yang sangat cepat. Basis data seperti CASME II telah banyak digunakan pada banyak penelitian terdahulu (Li et al., 2018), (Duque et al., 2018). Pada beberapa sampel video yang dihasilkan oleh CASME II menunjukkan gerakan ekspresi mikro yang diikuti dengan gerakan kecil pada bagian kepala. Gerakan-gerakan diluar gerakan pada area wajah ini akan mempengaruhi kinerja dari sistem pengenalan ekspresi mikro. Penelitian sebelumnya (Borza et al., 2017) menggunakan tahapan pra-pemrosesan untuk mendeteksi lokasi wajah berbasis landmark wajah (facial landmark) menggunakan basis data CASME II. Pada penelitian tersebut, metode yang diusulkan tidak memperhitungkan informasi dari gerakan kepala yang dihasilkan oleh CASME II.

Dari permasalahan tersebut, pada penelitian ini kami mengusulkan pendeteksian wajah serta melakukan pelacakan gerakan kepala untuk kestabilan lokasi pada wajah. Viola-Jones digunakan sebagai metode untuk mendeteksi wajah (Rosiani et al., 2018) secara akurat. Metode Viola-Jones merupakan framework pertama berdasarkan deteksi objek yang memberikan tingkat deteksi yang baik secara real-time (Vikram \& Padmavathi, 2017). Pelacakan gerakan wajah dilakukan dengan menggunakan metode palacakan berbasis titik fitur (point features) yaitu Kanade-Lucas-Tomasi (KLT). KLT dapat melacak wajah manusia secara real-time dalam sebuah deretan gambar.

Titik fitur yang menjadi acuan pelacakan wajah dengan KLT adalah ujung hidung. Pemilihan hidung sebagai acuan pelacakan adalah bentuk hidung yang menonjol dan selalu terlihat di kamera 
membuat lokasi hidung selalu dapat ditemukan dibandingkan fitur wajah yang lain (Canada et al., 2002). Untuk mendapatkan lokasi hidung dengan tepat, kami menggunakan metode Discriminative Response Map Fitting (DRMF) (Beh \& Goh, 2019) merupakan salah satu metode facial landmark yang menghasilkan keakuratan titik fitur wajah dengan baik (Asmara et al., 2019), (Rosiani et al., 2018).

Penelitian ini bertujuan melakukan pendeteksian wajah serta melacakan gerakan wajah dengan akurat secara real-time pada dataset CASME II dengan memanfaatkan metode pelacakan KLT. Diharapkan dengan pembentukan area wajah yang selalu terlacak dengan tepat ini, proses berikutnya dari pengenalan ekspresi mikro dapat berjalan dengan baik.

\section{Pra-pemrosesan Pengenalan Ekspresi Mikro}

Pada bagian ini menjelaskan garis besar dari Pra-pemrosesan pada sistem pengenalan ekspresi mikro yang ditunjukkan pada Gambar 1 .

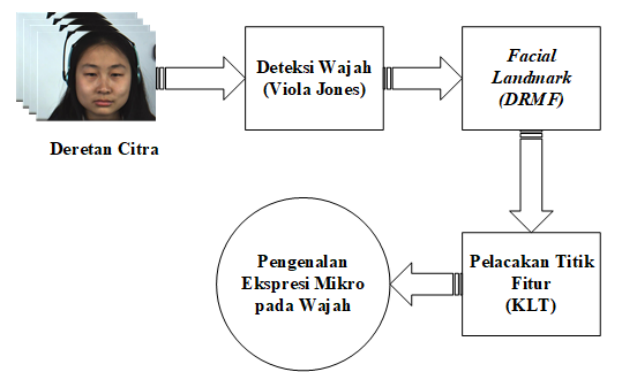

Gambar 1. Diagram Proses pada Metode yang Diusulkan

\subsection{Deteksi Wajah menggunakan Viola Jones}

Terdapat empat Langkah untuk mendeteksi wajah pada Viola Jones (Rosiani et al. 2018). Pertama, mengitung haar feature dengan cara pengurangan dari rata-rata piksel pada daerah gelap dan terang. Dari hasil perhitungan tersebut, jika nilai berada pada ambang batas (threshold) yang ditentukan, maka area tersebut dianggap ada. Fitur haar ditunjukkan pada Gambar 2, pencarian dimulai pada bagian ujung kiri dari citra.

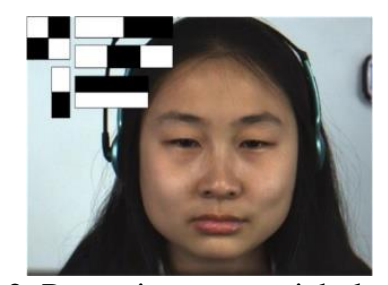

Gambar 2. Pencarian area wajah dengan haar feature

Kedua, perhitungan integral image yang bertujuan untuk menentukan hasil dari fitur haar dari proses sebelumnya. Ketiga, cascade classifier merupakan metode klasifikasi bertingkat untuk menghubungkan macam-macam fitur haar secara bertingkat. Dengan metode ini, maka proses klasifikasi membutuhkan waktu yang lebih cepat dengan mempertimbangkan pencarian objek yang berpusat pada daerah yang memiliki peluang besar dimana objek berada. Terakhir, dari semua proses dilakukan tahapan pelatihan agar kinerja metode lebih meningkat. Hasil dari metode ini adalah sebuah area Region of Interest (ROI) yang berbentuk kotak yang berada pada area wajah, ditunjukkan pada Gambar 3.

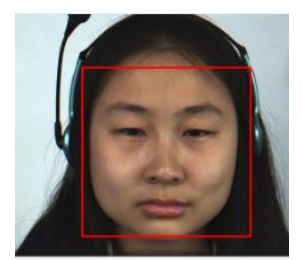

Gambar 3. Hasil ROI pada metode Viola Jones

\subsection{Penetuan titik fitur menggunakan Facial Landmark}

Setelah ROI wajah dibentuk seperti pada Gambar 3, selanjutnya sekumpulan fitur titik wal dihitung dengan mengekstraksi respon patch yang diikuti dengan proyeksi berdimensi rendah (low dimensional projection) (Liong et al., 2018) ditunjukkan pada Gambar 4.

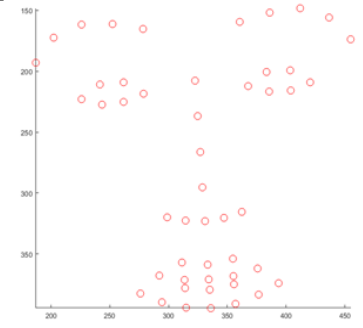

Gambar 4. Model DRMF dengan 49 titik

Berikutnya DRMF mengulangi titik fitur awal dengan menghubungkannya dengan target frame. Fitur yang dihasilkan mengontrol variasi bentuk dan tampilan yang dipelajari dari set pelatihan. Model statistik dari pola kemunculan dan variabilitas diterapkan dalam metode DRMF dengan akurat dalam hal pencarian.

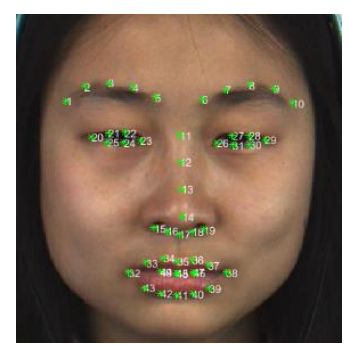

Gambar 5. Facial landmark dengan DRMF

Pada Gambar 5, titik-titik yang dihasilkan DRMF berjumlah 49 titik yang tersebar disetiap komponen wajah. Titik ke 1 sampai 10 berada pada area alis, titik ke 11 sampai 19 terletak pada bagian 
hidung, titik ke 20 sampai 31 terletak pada bagian mata dan titik ke 32 sampai 49 terletak pada bagian mulut. Kami hanya menggunakan titik ke 14 yang berada pada ujung hidung sebagai inisiasi awal proses pelacakan pada tahapan selanjutnya. Seluruh tahapan deteksi wajah, facial landmark dan penentuan titik fitur pelacakan hanya menggunakan frame pertama, yang bertujuan sebagai inisiasi proses pelacakan yang akan dijelaskan pada sub bab selanjutnya.

\subsection{Pelacakan Wajah dengan Metode Kanade Lucas Tomasi (KLT)}

Algoritma KLT digunakan sebagai metode pelacakan titik fitur yang paling popular. Algoritma KLT diperkenalkan oleh Lucas dan Kanade dan dikembangkan lagi oleh Tomasi dan Kanade (Belmont et al., 2018). Algoritma ini digunakan unutk mendeteksi titik-titik yang tersebar yang memiliki tektur yang cukup untuk melacak titik-titik yang dibutuhkan yang disebut good feature to track (Jianbo Shi \& Tomasi, 1994).

Algoritma KLT pada penelitian ini digunakan sebagai metode utuk melacak wajah manusia secara real-time pada sampel video. Cara kerja KLT yaitu menemukan parameter yang memungkinkan reduksi pengukuran ketidaksamaan antara titik fitur yang terkait dengan model translasi asli (Asmara et al., 2019).

Pertama, KLT menghitung perpindahan titik yang dilacak dari satu frame ke frame lain pada deretan citra masukan, perpindahan titik fitur dianalogikan pada Gambar 7. Hasil perhitungan perpindahan ini, akan sangat mudah untuk menghitung pergeseran kepala pada setiap frame. KLT melacak gerakan wajah dalam dua langkah sederhana, pertama menemukan titik fitur yang dapat dilacak di frame pertama dan kemudian melacak fitur yang terdeteksi di frame berikutnya dengan menggunakan perhitungan perpindahan.

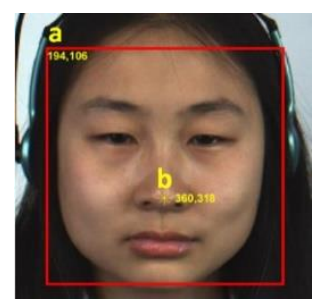

Gambar 6. Inisiasi Titik Fitur pada Frame Pertama.

(a) Koordinat awal pada ROI wajah dan (b)

Koordinat awal pada Titik Ujung Hidung

Pada tahapan sebelumnya, titik fitur pada ujung hidung telah didapatkan dengan metode DRMF pada titik ke-14 yang ditunjukkan pada Gambar 6 . Inisiasi titik fitur hanya diberikan pada frame pertama sebagai acuan pelacakan pada frame berikutnya. Selanjutnya titik fitur dilakukan pelacakan menggunakan optical flow (Ma et al., 2017), metode ini akan melakukan deteksi pada setiap titik yang telah diinisiasi dengan menghitung gerakan piksel pada citra.

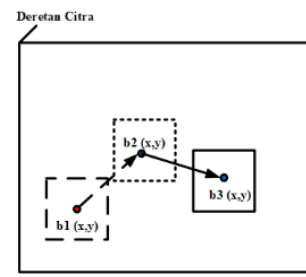

Gambar 7. Pergerakan Translasi pada deretan citra

Asumsikan bahwa salah satu titik sudut awal adalah $(x, y)$. Kemudian pada frame berikutnya, jika terjadi perpindahan oleh beberapa vektor variable disimbolkan dengan Persamaan 1.

$$
[b 1(x, y), b 2(x, y), b 3(x, y), \ldots . b n(x, y)]
$$

maka titik sudut yang dipindahkan dari frame berikutnya akan menjadi penjumlahan dari titik awal dan vektor yang dipindahkan Koordinat titik baru dijelaskan pada Persamaan 2 dan 3.

$$
\begin{aligned}
& x^{\prime}=x+b 1(x, y) \\
& y^{\prime}=y+b 2(x, y)
\end{aligned}
$$

Maka, perpindahan yang terjadi saat ini dihitung untuk setiap koordinat yang ada. Dengan ini, kami menggunakan fungsi warp (warp function) yang merupakan fungsi dengan koordinat dan parameter yang dilambangkan pada Persamaan 4 .

$$
W(x ; p)=(x+b 1 ; x+b 2)
$$

Fungsi warp digunakan untuk memperkirakan formasi dari setiap titik.

Pada setiap pelacakan yang dilakukan di setiap frame, koordinat pada setiap titik fitur disimpan sebagai data yang akan dihitung untuk menstabilkan ROI wajah pada setiap frame.

\section{Hasil dan Pembahasan}

Pengujian menggunakan basis data dari CASME II. Kami menggunakan sampel yang berjumlah 6 video yang telah dipilih secara manual dengan mempertimbangkan gerakan ekspresi yang diikuti dengan gerakan kepala. Keterangan dari sampel video terpilih dapat dilihat pada Tabel 1.

Tabel 1. Rincian Sampel Video pada Data Uji

\begin{tabular}{llll}
\hline No & Ekspresi & Nama & Frame \\
\hline 1 & Disgust & 11_EP13_05f & 176 \\
2 & Disgust & 05_EP09_05f & 424 \\
3 & Disgust & 17_EP02_01 & 296 \\
4 & Happiness & 14_EP09_04 & 146 \\
$\mathbf{5}$ & Happiness & 09_EP06_02f & $\mathbf{2 0 0}$ \\
6 & Surprise & 25_EP12_01 & 364 \\
\hline & & Jumlah Frame & $\mathbf{1 6 0 6}$ \\
\hline
\end{tabular}


Tabel 2. Perbandingan Koordinat ROI Wajah dengan Pelacakan dan Tanpa Pelacakan

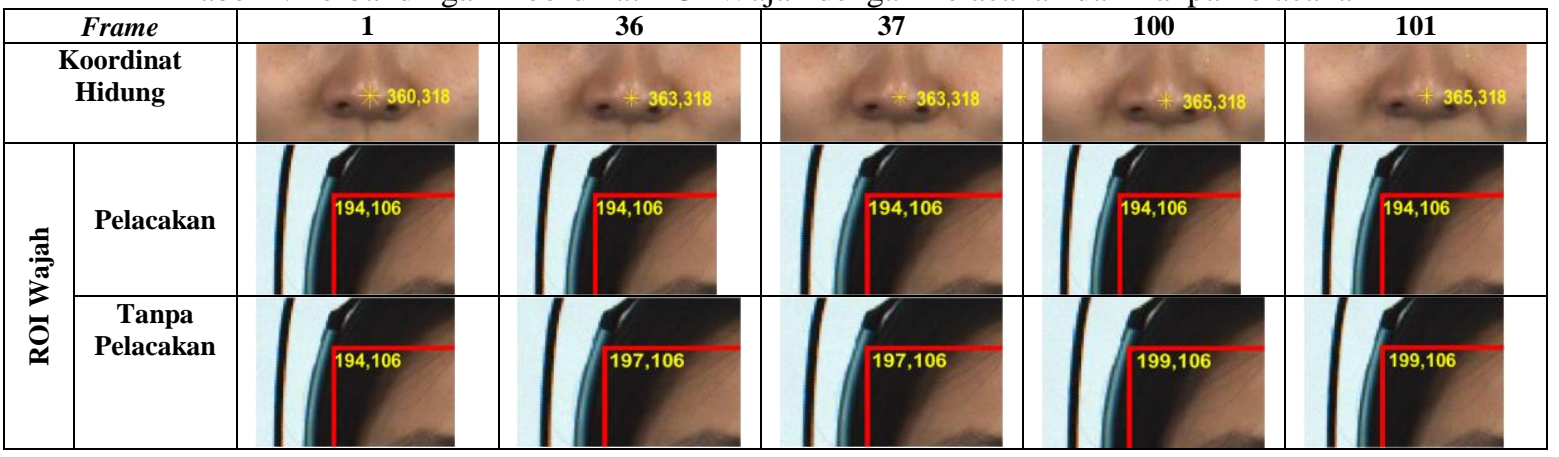

Percobaan ini menggunakan sampel emosi mikro berlabel Happiness dengan nama file 09_EP06_02f yang memiliki deretan gambar sejumlah 200 frame. Pada percobaan ini, kami menampilkan 8 frame dengan urutan deretan citra ke2, 36, 37, 100, 101, 102, 131 dan 200.

\subsection{Deteksi Wajah}

Hasil deteksi wajah pada sampel video Happiness - 09_EP06_02f menunjukkan ROI yang dihasilkan dengan metode Viola Jones selalu akurat pada posisi wajah di setiap deretan gambar yang diproses. ROI ditunjukkan dengan bentuk segi empat yang memiliki garis berwarna merah, ditunjukkan pada Gambar 6. Berdasarkan pengujian deteksi wajah pada setiap sampel video yang telah diuji coba, selanjutnya pada Tabel 3 menunjukkan jumlah ketepatan lokasi yang dihasilkan dari setiap data uji pada Tabel 1.

Tabel 3. Hasil deteksi wajah pada setiap data uji

\begin{tabular}{ccccc}
\hline No & Nama & Terdeteksi & Hasil \\
\hline & 11_EP13_05f & $\checkmark$ & $\checkmark$ & \\
3 & 05_EP09_05f & $\checkmark$ & \\
4 & 14_EP02_01 & $\checkmark$ & \\
5 & 09_EP06_02f & $\checkmark$ & \\
6 & 25_EP12_01 & $\checkmark$ &
\end{tabular}

\subsection{Pelacakan Wajah}

Pada sampel video Happiness - 09_EP06_02f jika dilihat pada video dengan cara manual, gerakan emosi yang muncul disertai dengan gerakan kepala yang bergeser ke arah kanan kemudian bergerak sedikit keatas. Pada sistem pengenalan ekspresi mikro, gerakan kepala yang termasuk bagian dari non ekspresi akan berpengaruh besar pada proses pengenalan ekspresi mikro. Untuk mengatasi permasalahan tersebut, pada bagian ini akan dilakukan percobaan untuk mendeteksi gerakan yang terjadi pada wajah yang bertujuan untuk kestabilan pendeteksian area wajah.

Setelah area wajah terdeteksi, selanjutnya sistem melakukan pelacakan pada setiap frame pada sampel video yang telah ditentukan dengan metode KLT. Kami menggunakan ujung hidung sebagai acuan pelacakan pada wajah. Tabel 2 merupakan hasil pelacakan dari KLT, pada gambar tersebut terdapat 5 frame yang telah dipilih sebelumnya dengan titik koordinat yang telah terlacak pada setiap framenya. Masing-masing titik fitur pada setiap frame memiliki nilai koordinat yaitu nilai $\mathrm{x}$ dan y yang merupakan lokasi dari titik pada ujung hidung.

Tabel 4. Perhitungan Perpindahan Koordinat ROI pada Wajah Berdasarkan Hasil Pelacakan pada Titik Hidung

\begin{tabular}{ccccccc}
\hline \multirow{2}{*}{$\begin{array}{c}\text { Fram } \\
\boldsymbol{e}(\boldsymbol{t})\end{array}$} & \multicolumn{2}{c}{$\begin{array}{c}\text { Koordinat } \\
\text { Hidung }(\boldsymbol{k h})\end{array}$} & \multicolumn{2}{c}{$\begin{array}{c}\text { Perpind } \\
\text { ahan }(\boldsymbol{p})\end{array}$} & \multicolumn{2}{c}{$\begin{array}{c}\text { Koordinat } \\
\text { Wajah }(\boldsymbol{k w})\end{array}$} \\
\cline { 2 - 7 } & $\mathbf{X}$ & $\mathbf{Y}$ & $\mathbf{X}$ & $\mathbf{Y}$ & $\mathbf{X}$ & Y \\
\hline $\mathbf{1}$ & 360 & 318 & - & - & 194 & 106 \\
$\mathbf{3 6}$ & 363 & 318 & 3 & 0 & 197 & 106 \\
$\mathbf{3 7}$ & 363 & 318 & 0 & 0 & 197 & 106 \\
$\mathbf{1 0 0}$ & 365 & 318 & 2 & 0 & 199 & 106 \\
$\mathbf{1 0 1}$ & 365 & 318 & 0 & 0 & 199 & 106 \\
$\mathbf{1 0 2}$ & 365 & 318 & 0 & 0 & 199 & 106 \\
$\mathbf{1 3 1}$ & 366 & 318 & 1 & 0 & 200 & 106 \\
$\mathbf{2 0 0}$ & 365 & 316 & -1 & -2 & 199 & 104 \\
\hline
\end{tabular}

Sebagai contoh, pada frame ke-2 titik pada hidung yang telah ditandai berada pada koordinat $x=$ 360 dan $y=318$, sedangkan pada frame ke-36 
koordinat $x=363$ dan $y=318$. Dalam hal ini, perubahan nilai koordinat yang dihasilkan pada frame ke-2 dan frame ke-36 terdapat pada nilai koordinat $\mathrm{x}$. Seluruh data koordinat pada kedelapan frame ditunjukkan pada Tabel 4.

Pada Tabel 4, terdapat nilai koordinat pada titik hidung yang terlacak pada setiap frame. Untuk membuat lokasi pada ROI wajah selalu stabil, maka nilai $x$ dan $y$ pada ROI mengikuti pergerakan dari titik fitur pada hidung. Dengan melakukan perhitungan operasi dasar seperti pada Persamaan 5 .

$$
p(x)=k h(x, t+1)-k h(x, t)
$$

$$
p(y)=k h(y, t+1)-k h(y, t)
$$

dimana $p$ adalah jarak perpindahan pada kedua elemen $x$ dan $y, t$ adalah urutan frame, $k h$ merupakan nilai koordinat hidung dan $k h$ adalah nilai koordinat dari ROI wajah. Sebagai contoh, untuk mendapatkan jarak dari koordinat dari nilai $x$ dan y pada frame ke36 menggunakan Persamaan 5.

$$
\begin{aligned}
& p(x)=363-360=3 \\
& p(y)=318-318=0
\end{aligned}
$$

maka diperoleh hasil pergeseran dari nilai $x$ dari frame ke 1 dan ke 36 sebesar $p(x)=3$ dan $p(y)=$ 0 . Untuk membuat ROI wajah pada frame ke-36 mengikuti pergeseran dari titik hidung, maka dilakukan perhitungan pada Persamaan 7 dan 8 .

$$
\begin{aligned}
k w(x) & =k w(x)+p(x) \\
& =194+3 \\
& =197 \\
k w(y) & =k w(y)+p(y) \\
& =106+0 \\
& =106
\end{aligned}
$$

Dari percobaan diatas, seluruh hasil perhitungan pada setiap frame dapat dilihat pada Tabel 4. Gambar 8 merupakan sebuah grafik untuk mengetahui arah gerakan yang dihasilkan dari pelacakan titik hidung. Pada gambar tersebut menunjukkan pergerakan dimulai pada titik koordinat $x=360$ dan $y=318$, titik ini merupakan inisiasi awal pada frame pertama. Selanjutnya titik tersebut bergerak ke arah kanan pada frame ke-1, 36, 37, 100, 101,102 , dan 131, kemudian bergerak ke arah atas pada frame ke-200.

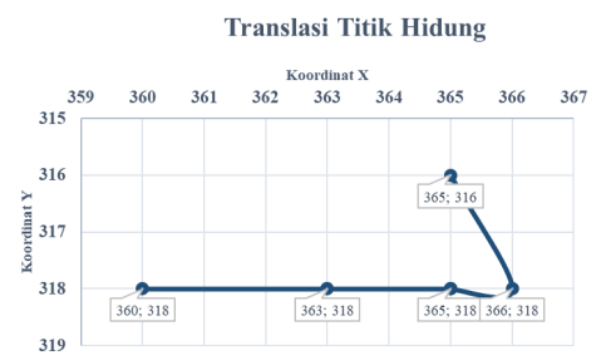

Gambar 8. Gerakan dari Pelacakan Titik Fitur pada Hidung

Dari pelacakan titik hidung, selanjutnya ROI wajah harus mengikuti gerakan titik hidung agar area pada wajah yang ditangkap lebih stabil. Gambar 9 menunjukkan gerakan yang dihasilkan ROI wajah setelah dilakukan proses penyesuaian dari titik hidung yang telah dilacak.

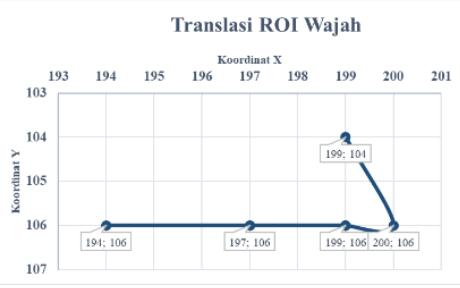

Gambar 9. Gerakan ROI Wajah setelah dilakukan penyesuaian dari Titik Hidung

\subsection{Pengukuran Akurasi Pelacakan Wajah}

Kinerja sistem diukur menggunakan presentasi dari akurasi untuk mengukur seberapa bagus kinerja dari suatu sistem. Pada penelitian ini kami menggunakan pengukuran akurasi binary karena memiliki dua keluaran kelas yaitu terdeteksi atau tidak terdeteksi. Kami menggunakan confusion matrix untuk menghitung akurasi dengan dua kelas yang dijelaskan pada Persamaan 9.

akurasi $=\frac{T P+T N}{T P+T N+F P+F N} \times 100$

\begin{tabular}{|c|c|c|c|c|}
\hline \multirow[b]{2}{*}{ No } & \multirow[b]{2}{*}{ Nama } & \multirow[b]{2}{*}{ Frame } & \multicolumn{2}{|c|}{ Pelacakan Fitur } \\
\hline & & & Deteksi & $\begin{array}{c}\text { Tidak } \\
\text { Terdeteksi }\end{array}$ \\
\hline 1 & 11_EP13_05f & 176 & 176 & 0 \\
\hline 2 & 05_EP09_05f & 424 & 424 & 0 \\
\hline 3 & 17_EP02_01 & 296 & 296 & 0 \\
\hline 4 & 14_EP09_04 & 146 & 146 & 0 \\
\hline 5 & 09_EP06_02f & 200 & 200 & 0 \\
\hline \multirow[t]{2}{*}{6} & 25_EP12_01 & 364 & 364 & 0 \\
\hline & & Jumlah & 1606 & $\mathbf{0}$ \\
\hline
\end{tabular}

dimana TP (True Positive), TN (True Negative), FP (False Positive), FN (False Negative). TP merupakan data positif terdeteksi sebagai data positif. TN yaitu jumlah data negatif yang terdeteksi negatif. Sedangkan FP merupakan data negatif yang terdeteksi positif dan FN merupakan jumlah data positif yang terdeteksi negatif (Rosiani et al. 2018; Sokolova and Lapalme 2009).

Tabel 5. Hasil Pelacakan dengan Metode KLT

Berikut ini merupakan hasil pengujian yang dilakukan pada seluruh basis data yang ditunjukkan pada Tabel 5. Pada Tabel 5, menunjukkan pada setiap frame dalam sampel video, seluruh titik fitur yang dilacak selalu terdeteksi dengan benar. Selanjutnya, dari hasil Tabel 5, dilakukan proses perhitungan akurasi dengan mengimplementasikan ke dalam tabel confusion matrix seperti pada Gambar 10.

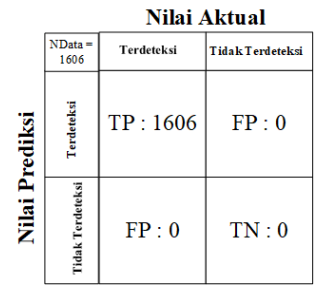

Gambar 10. Confusion Matrix pelacakan dengan

KLT 
Dari perhitungan akurasi menghasilkan tingkat akurasi sebesar $100 \%$ yang artinya titik fitur di sudut hidung seluruhnya terlacak pada seluruh frame.

$$
\text { Akurasi }=\frac{1606+0}{1606+0+0+0} \times 100 \%=100 \%
$$

\subsection{Pengukuran Akurasi Pengenalan Ekspresi Mikro}

Kestabilan wajah pada pengenalan ekspresi mikro sangat penting untuk dilakukan untuk mengurangi gerakan yang tidak diperlukan dalam proses pengenalan. Pada penelitian (Borza et al., 2017), menggunakan tahapan pra-pemrosesan tanpa memperhitungkan gerakan kepala yang bukan gerakan dari ekspresi mikro. Hasil perbandingan akurasi dari penelitian terdahulu dengan hasil yang diusulkan dapat dilihat pada Tabel 6. Dari tabel tersebut dapat dilihat bahwa pengenalan ekspresi mikro dengan melakukan pelacakan kepala untuk meminimalisir gerakan diluar ekspresi menghasilkan akurasi sebesar 86,6\% lebih baik dari penelitian sebelumnya dengan akurasi $81,75 \%$.

Tabel 6. Komparasi hasil pengenalan ekspresi mikro

\begin{tabular}{|c|c|c|c|}
\hline Penulis & $\begin{array}{c}\text { Pra- } \\
\text { pemrosesan }\end{array}$ & Klasifikasi & Hasil \\
\hline $\begin{array}{c}\text { (Borza et al., } \\
\text { 2017) }\end{array}$ & $\begin{array}{c}\text { Deep neural } \\
\text { network }\end{array}$ & LOSO & $81,75 \%$ \\
\hline $\begin{array}{c}\text { Metode } \\
\text { yang } \\
\text { diusulkan }\end{array}$ & DRMF & $\begin{array}{c}\text { Neural } \\
\text { Network }\end{array}$ & $\mathbf{8 6 , 6 \%}$ \\
\hline
\end{tabular}

\section{Kesimpulan dan Saran}

Pendeteksian dan pelacakan lokasi wajah pada ekspresi mikro dengan metode KLT memberikan hasil terbaik. Dari percobaan yang telah dilakukan dengan 6 sampel video terpilih secara manual dengan mempertimbangkan gerakan ekspresi yang diikuti dengan gerakan kepala pada basis data CASME II. Pada percobaan deteksi wajah yang dilakukan dengan menggunakan metode Viola Jones memberikan hasil yang akurat pada setiap frame di seluruh sampel video. Sedangkan pada proses pelacakan titik fitur pada ujung hidung di setiap frame pada data uji memberikan nilai akurasi sebesar $100 \%$. Pengenalan ekspresi mikro ekspresi dengan pelacakan kepala dilakukan pada penelian ini, dengan menghasilkan tingkat akurasi sebesar 86,6\% lebih baik daripada penelitian (Borza et al., 2017) yang memiliki akurasi sebesar $81,75 \%$. Penelitian selanjutnya akan mengimplementasikan deteksi dan pelacakan titik fitur dengan metode KLT dalam pengenalan ekspresi mikro dengan basis data yang lain.

\section{Daftar Pustaka:}

Asmara, R. A., Choirina, P., Rahmad, C., Setiawan, A., Rahutomo, F., Yusron, R. D. R., \& Rosiani, U. D. (2019). Study of DRMF and ASM facial landmark point for micro expression recognition using KLT tracking point feature. Journal of Physics: Conference Series, 1402, 077039. Link

Beh, K. X., \& Goh, K. M. (2019). Micro-Expression Spotting Using Facial Landmarks. 2019 IEEE 15th International Colloquium on Signal Processing Its Applications, 192-197. Link

Belmont, B., Kessler, R., Theyyunni, N., Fung, C., Huang, R., Cover, M., Ward, K. R., Shih, A. J., \& Tiba, M. (2018). Continuous Inferior Vena Cava Diameter Tracking through an Iterative Kanade-LucasTomasi-Based Algorithm. Ultrasound in Medicine \& Biology, 44(12), 2793-2801.

Borza, D., Danescu, R., Itu, R., \& Darabant, A. (2017). High-speed video system for micro-expression detection and recognition. Sensors, 17(12), 2913.

Canada, C., Gorodnichy, D. O., Malik, S., \& Roth, G. (2002). Nouse 'Use Your Nose as a Mouse'-A new technology for hands-free games and interfaces. In: Proceedings of Vision Interface, 354-361.

Duque, C. A., Alata, O., Emonet, R., Legrand, A.-C., \& Konik, H. (2018). Micro-expression spotting using the Riesz pyramid. 2018 IEEE Winter Conference on Applications of Computer Vision (WACV), 66-74.

Ekman, P., \& Friesen, W. V. (1971). Constants across cultures in the face and emotion. Journal of Personality and Social Psychology, 17(2), 124.

Jianbo Shi, \& Tomasi. (1994). Good features to track. 1994 Proceedings of IEEE Conference on Computer Vision and Pattern Recognition, 593-600. Link.

Li, X., Hong, X., Moilanen, A., Huang, X., Pfister, T., Zhao, G., \& Pietikäinen, M. (2018). Towards Reading Hidden Emotions: A Comparative Study of Spontaneous Micro-Expression Spotting and Recognition Methods. IEEE Transactions on Affective Computing, 9(4), 563-577.

Liong, S.-T., See, J., Wong, K., \& Phan, R. C.-W. (2018). Less is more: Micro-expression recognition from video using apex frame. Signal Processing: Image Communication, 62, 82-92. Link

Ma, H., An, G., Wu, S., \& Yang, F. (2017). A region histogram of oriented optical flow (RHOOF) feature for apex frame spotting in micro-expression. 2017 International Symposium on Intelligent Signal Processing and Communication Systems (ISPACS), 281-286.

Rosiani, U. D., Ririd, A. R. T. H., Choirina, P., Sooai, A. G., Sumpeno, S., \& Purnomo, M. H. (2018). Micro Expression: Comparison of Speed and Marking Accuracy in Facial Component Detection. 2018 International Conference on Computer Engineering, Network and Intelligent Multimedia (CENIM), 221226. Link

Vikram, K., \& Padmavathi, S. (2017). Facial parts detection using Viola Jones algorithm. 2017 4th International Conference on Advanced Computing and Communication Systems (ICACCS), 1-4. 